\title{
Physicochemical, Phytochemical, Heavy Metal and Microbiological Analysis of Moringa oleifera Lam. Leaves
}

\author{
Emelia Oppong Bekoe ${ }^{1, *}$, Yakubu Jibira ${ }^{2}$, Gladys Amponsah Agyei ${ }^{1}$
}

Emelia Oppong Bekoe ${ }^{1, *}$, Yakubu Jibira², Gladys Amponsah Agyei ${ }^{1}$

'Department of Pharmacognosy \& Herbal Medicine, School of Pharmacy, University of Ghana, GHANA.

${ }^{2}$ Department of Pharmacology, Kwame

Nkrumah University of Science and

Technology, Kumasi, GHANA

\section{Correspondence}

\section{Emelia Oppong Bekoe}

Department of Pharmacognosy \& Herbal Medicine, School of Pharmacy, University of Ghana, GHANA

E-mail: eobekoe@ug.edu.gh

History

- Submission Date: 11-07-2020;

- Review completed: 19-08-2020;

- Accepted Date: 02-09-2020.

DOI : 10.5530/pj.2020.12.211

Article Available online http://www.phcogj.com/v12/i6s

\section{Copyright}

(C) 2020 Phcogj.Com. This is an openaccess article distributed under the terms of the Creative Commons Attribution 4.0 International license.

\section{ABSTRACT}

Background: Moringa oleifera leaves is one of the highly patronized herbs on the Ghanaian market. It is used for the treatment and prevention of several diseases. It is imperative that available and effective methods can be utilized to assess the quality of samples before being consumed. Objective: A study of the leaves was conducted to ascertain its physicochemical, phytochemical, heavy metal and microbiological content to develop a simple but acceptable criteria which could be useful in ensuring the quality of this crude drug. Materials and Methods: The qualitative and quantitative morphological features, physicochemical, phytochemical, microbial load and flouresent features of the leaves of $M$. oleifera were evaluated. Results: $M$. oleifera leaves were found to be glaborous with opposite leaflet, leaflet tripinnate, with a micronate apex and possessing an entire margin. Microscopy showed vein islets, rosette calcium oxalate crystals, polygonal epidermal cells and unicellular trichomes. The $50 \%$ ethanol soluble extractives of $M$. oleifera were highest, followed by the water and petroleum ether. Tannins, alkaloids, gylcosides, phenols, flavonoids, phenols, gums, and mucilage were present. Conclusion: The documented pharmacognostic features may be used as part of daily protocols to correctly identify and determine the quality of the the crude plant. The preliminary phytochemical, heavy metal and microbiological limits can be further used to ascertain the quality of raw materials of $M$. oleifera before they are used.

Key Words: Physicochemical, Pharmacognostic, Fluorescence, Heavy metal, Microbiological.

\section{INTRODUCTION}

Plants continue to serve as valuable therapeutic agents, and are an integral part of both modern and traditional systems of medicine. The patronage of natural therapies in the management and treatment of diseases have been on the rise. This can be attributed to the massive contribution made by herbal medicines towards providing effective therapeutic outcomes. Poverty and limited access to modern medicine have caused a high percentage of the world's population, especially those living in developing countries to use plant medicine as their primary source of health care. ${ }^{1}$ Evidently, most of the traditional systems of medicines are effective, but lack standardization or quality control parameters for evaluating the herbal medicines. ${ }^{2}$ The safety and efficacy of herbal materials largely require monitoring the quality of the product from the collection, through processing, to the finished product. Standardization and quality control of herbal medicine involves physico-chemical evaluation of crude drugs whereby attention is usually given to indices such as authentication, foreign matter content, organoleptic evaluation, diagnostic tissue features present in drug powder, ash values, extractive values, moisture content determination, chromatographic and spectroscopic evaluation, determination of pesticide residues, microbial contamination, aflatoxins and radioactive contamination. ${ }^{3}$ As such, the need for standardization is essential, given the global acceptance of herbal products as remedies for various ailments.
Moringa oleifera Lam. of the family Moringaceae is commonly known as horse radish or drumstick tree and ranges in height from 5 to $10 \mathrm{~m}$. It is found mostly in Africa, India, Arabia, Southeast Asia, the Pacific and Caribbean Islands. ${ }^{4-6}$ This plant is among the most widely patronized herbal medicines on the Ghanaian market. ${ }^{7}$ The leaves are small and oval to ovate, with leaflets averaging $1-2 \mathrm{~cm}$ in length and $5-10 \mathrm{~cm}$ in width. All parts of the plant, bark, fruit, leaves, nuts, seeds, tubers, roots and flowers have rich folkloric usage against a variety of ailments such as fever, abscess, wound, infections, diabetes, asthma, urinary tract infection, gastric ulcer, several metabolic diseases, including hypercholesterolemia, high blood pressure, non-alcoholic liver disease, cancer and inflammation Pharmacological studies have also demonstrated the ability of this plant to have corresponding biological activities which substantiate its use in the afore mentioned disease states. $^{7-10}$ Additionally the moringa is known to have analgesic, antipyretic, anticancer, hepatoprotective, antioxidant, antiepileptic, nootropic, anti-allergic, local anesthetic, anthelmintic, antimicrobial, wound healing, immunomodulatory, and antidiarrheal properties. $5,10,11$ The genus Moringa consists of 13 plant species. Moringa species are well-known for their antioxidant, anticancer, anti-inflammatory, and antidiabetic properties. Their biological activities have been attributed to the high content of flavonoids, glucosinolates, and glucosides. ${ }^{9}$ Studies have been conducted on the nutritional value and bio-active constituents of these herbs. ${ }^{12} \mathrm{M}$. oleifera is one of the richest plant sources of nutrients,

Cite this article: Bekoe EO, Jibira Y, Agyei GA. Physicochemical, Phytochemical, Heavy Metal and Microbiological Analysis of Moringa oleifera Lam. Leaves. Pharmacogn J. 2020;12(6) Suppl:1541-6. 
including minerals, proteins and various vitamins such as $\mathrm{A}, \mathrm{B}, \mathrm{C}, \mathrm{D}$, $\mathrm{E} \& \mathrm{~K}$. The vital minerals present in Moringa include calcium, copper, iron, potassium and zinc. ${ }^{6,11,13}$ Other active ingredients present in the leaves include; pterygospermin, spirochin, moringic acid, niazinin $\mathrm{A}$ and B, niazimicin, campesterol and saponins. Moringa oleifera leaves have been established to have a high consumption rate in Ghana. The sales of these herbs have been discovered to increase the income of some Ghanaian farmers resulting in its high demand. ${ }^{5,14}$

The quality parameters for plants established in other countries cannot always be directly transferred for evaluating the parameters of these herbs, due to variations in environmental conditions. The lack of criteria for quality control specifications of these plants could result in contamination or adulteration either through ignorance or fraud with other substances which can ultimately affect the final drug product. ${ }^{15}$ Hence, the physicochemical, phytochemical, heavy metal and microbiological studies of the leaves of M. oleifera was carried out to develop acceptable characteristics which could be useful in ensuring the quality of these plants.

\section{MATERIALS AND METHODS}

\section{Plant materials}

The leaves of M. oleifera were harvested from the Botanical gardens of University of Ghana, on the 15th of October, 2018. They were identified and authenticated at the Department of Plant and Environmental Science, University of Ghana (UG), Legon and the herbarium specimen deposited at Department of Pharmacognosy and Herbal medicine, School of Pharmacy, UG, Legon. Fresh samples were kept in glycerine, and later used for the organoleptic and microscopic determinations. One kilogram leaves and sepals were air-dried for three (3) weeks, pulverised and stored in air tight containers.

\section{Macroscopic evaluation}

The organoleptic properties of this plant material were investigated by documenting both the morphological and sensory characteristics. The morphological parameters of interest include the size, nature, colour, shape, texture, odour and surface, apex, type, margin and petiole surface of the leaves, margin and shape of the plant samples. The sensory characteristic documented were colour, taste, appearance, and texture of the drug.

\section{Microscopic evaluation}

Qualitative and quantitative microscopic features were evaluated with the Leciad compound light microscope observed under $\times 40$ magnification. These features of the sample were evaluated using standard protocols of WHO Guidelines on Quality Control Methods for Herbal Materials, 2011. ${ }^{3}$

\section{Physico-chemical analysis}

The extractive values, total ash, water soluble ash, foreign organic matter, foaming index, swelling index, moisture content, and acid insoluble ash were determined on the dried powdered leaves by established protocols. ${ }^{3,16}$

\section{Preliminary phytochemical screening}

Test for saponins, tannins, alkaloids, gylcosides, anthraquinones, phenols, flavonoids, gums, and mucilage were the preliminary phytochemical screening tests conducted on both the leaves of Moringa oleifera. ${ }^{17,18}$

\section{Fluorescence studies}

Fluorescence analysis of the powdered leaves of M. oleifera was carried out to determine the characteristic colour that will be emitted in specific solvents. The solutions obtained were observed under visible day light, UV light of short wavelength $(254 \mathrm{~nm})$, and UV light of long wavelength $(365 \mathrm{~nm})$. The solvents used were distilled water, 95 $\%$ ethanol, chloroform, methanol, glacial acetic acid, sulphuric acid, nitric acid, $1 \mathrm{~N}$ Hydrochloric acid, $\mathrm{FeCl}_{3}$, and $1 \mathrm{~N} \mathrm{NaOH}$. This protocol is widely used in pharmacognostic studies. ${ }^{19,20}$

\section{Heavy metal analysis}

Heavy metal analysis was performed following Frimpong-Mansah et al, 2016 described methods. ${ }^{[21]}$ An Olympus Vanta M Portable EDXRF (VMR) analyzer (USA) equipped with 4-Watt x-ray tube with application optimized anode material rhodium (Rh) and tungsten (W), $50 \mathrm{kV} \mathrm{x}$-ray tube and large area silicon drift detector was used to analyze the samples for heavy metals. The SARM 2711A, certified reference material and silica from the manufacturer was employed in the calibration of the XRF. The powdered sample of M. oleifera was passed through a stainless steel $850 \mu \mathrm{m}$ mesh (no.20) to obtained powders of uniform particle size. Four grams of each original sample was measured using an electronic balance and mix with 0.9 grams Fluxana H Electronic BM-0002-1(Lincowax C micro powder PM-Hoechst wax) as a binder in the mortar. The pellets were placed individually under the HHED-XRF and the results recorded on a PC monitor. Measurements were done in triplicates.

\section{Microbial evaluation}

\section{Determination of bacterial count}

One (1) gram of the powdered leaves of M. oleifera was weighed into $100 \mathrm{~mL}$ of sterile water in a tube to form a stock concentration. After multiple serial dilutions of $1: 99$, one (1) $\mathrm{mL}$ of each content was taken and added to their corresponding petri dishes containing $15 \mathrm{~mL}$ of plate count agar at $45{ }^{\circ} \mathrm{C}$. The dishes were inverted and incubated at $37{ }^{\circ} \mathrm{C}$ for 48 hours and the colonies formed were counted. ${ }^{[3]}$ This experiment was performed in triplicates. Bacillus subtilis ATCC 6538-P was used as growth controls for bacteria in the nutrient agar. ${ }^{3}$

\section{Determination of fungal count}

One (1) gram of the powdered leaves of M. oleifera was weighed into $100 \mathrm{~mL}$ of sterile water in a tube to form a concentration. A stock concentration of $10 \mathrm{mg} / \mathrm{mL}$ of pure chloramphenicol was prepared in methanol. $0.7 \mathrm{~mL}$ of the stock solution was taken and added to $350 \mathrm{~mL}$ of the potato dextrose agar to make a concentration of $20 \mathrm{ug} / \mathrm{mL}$. One (1) $\mathrm{mL}$ of each content of plant sample solution was taken and added to their corresponding petri dishes containing $15 \mathrm{~mL}$ of chloramphenicol potato dextrose agar at $45^{\circ} \mathrm{C}$. The petri dishes were inverted and incubated at room temperature for seven (7) days and the colonies were counted. Candida albicans ATCC 2091 was used as the fungal growth control for potato dextrose agar. ${ }^{3}$ All experiments were performed in triplicates.

\section{Statistical analysis}

Data are presented as mean \pm standard error of mean (SEM). Analyses were carried out with GraphPad for Windows (GraphPad Software Inc., San Diego, CA, USA).

\section{RESULTS}

Examination on $M$. oleifera leaves as displayed in Figure 1, revealed details such as the nature, colour, shape, texture, odour and surface, apex, type, margin and petiole surface of the leaves. Deatails are provided in Table 1 . The leaf of $M$. oleifera is a distinctively tripinnate compound with an entire margin.

The microscopic features of $M$. oleifera leaf section included the observation of vein islets, veinlet termination, secretory cells, unicellular trichomes and hexagonal epidermal as indicated in Figure 2. 


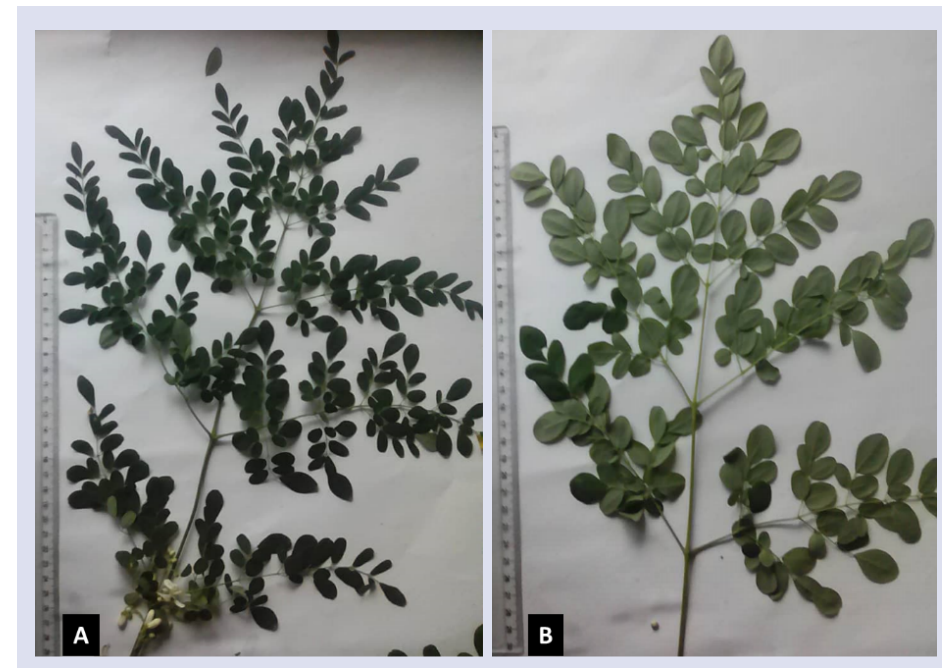

Figure 1: Upper (A) and lower (B) surfaces of M. oleifera leaves.

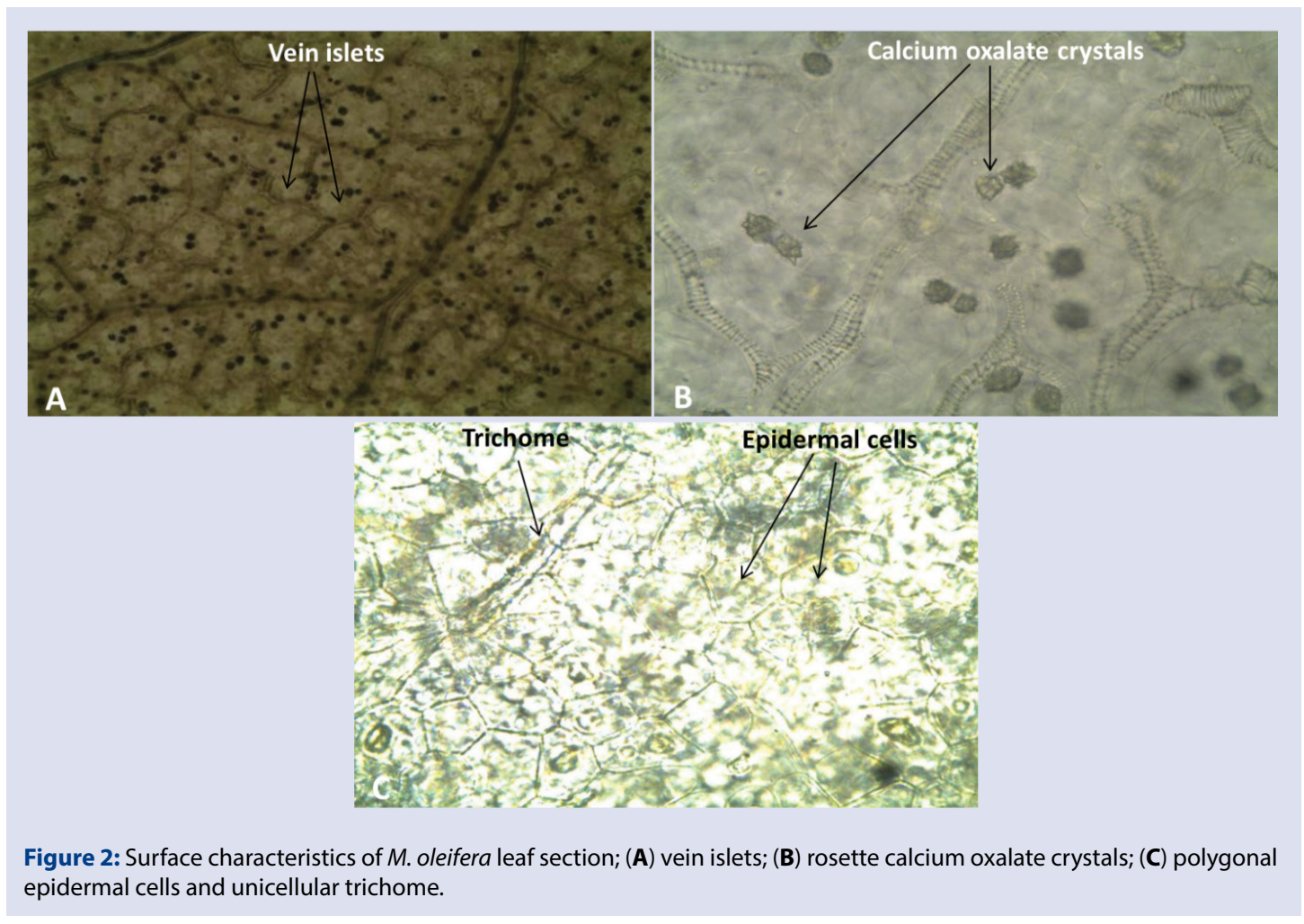

Table 1: Macroscopic features of $M$. oleifera leaves.

\begin{tabular}{cc}
\hline Parameters & Description \\
\hline Nature & Fresh \\
Colour & Green \\
Texture & Smooth \\
Surface & Glaborous \\
Odour & Bland \\
Leaflet arrangement & Opposite \\
Apex & Micronate \\
Type & Tripinnate compound leaf \\
Margin & Entire \\
\hline
\end{tabular}

The average $50 \%$ ethanol soluble extractives of $M$. oleifera were higher than that of the water and petroleum ether (Table 2). The physicochemical parameters of the leaf extract of M. oleifera are shown in Table 3. The foaming index, which was more than 100, indicates the presence ofsaponins in $M$. oleifera leaves. M. oleifera leaves also gave a swelling index of 5 , which may denote the presence of constituents such 
Table 2: Extractive values of $M$. oleifera.

\begin{tabular}{cc}
\hline Parameters & M. oleifera leaves $(\% \mathrm{w} / \mathrm{w})$ \\
\hline Petroleum ether & $15.33 \pm 1.5$ \\
$\mathbf{5 0}$ \% ethanol & $41.67 \pm 2.0$ \\
Water & $36.67 \pm 1.8$ \\
\hline
\end{tabular}

Table 3: Physico-chemical parameters of $M$. oleifera.

\begin{tabular}{cc}
\hline Parameters & M. oleifera leaves (\% w/w) \\
\hline Total Ash & $9.94 \pm 1$ \\
Acid insoluble ash & $5.72 \pm 1$ \\
Water soluble ash & $9.64 \pm 1$ \\
Moisture content & $14.6 \pm 1$ \\
Foreign organic matter & $\mathrm{Nil}$ \\
Foaming index & $200 \pm 20$ \\
Swelling index & $5 \pm 1$
\end{tabular}

Table 4: Fluorescence of $M$. oleifera leaves in different reagents

\begin{tabular}{cccc}
\hline Powdered plant sample + reagent & Daylight & Short wavelength $(\kappa 254 \mathrm{~nm})$ & Long wavelength $(\kappa 365 \mathrm{~nm})$ \\
\hline Distilled water & Light green & Brown & Green \\
$1 \mathrm{~N} \mathrm{HCl}$ & Light brown & Ash & Prown \\
$1 \mathrm{~N} \mathrm{NaOH}$ & Deep brown & Pink & Ash \\
$10 \mathrm{~N} \mathrm{Sulphuric} \mathrm{acid}$ & Light green & Pink & Ash \\
Methanol & Deep green & Pink & Brown \\
Glacial acetic acid & Brownish green & Ash & Green \\
Nitric acid & Orange & Pink & Ash \\
Chloroform & Green & Pink & Brown \\
$50 \%$ Ferric chloride & Brown & Pink & Ash \\
$95 \%$ Ethanol & Light green &
\end{tabular}

as gums and mucilage. ${ }^{3}$ The different solvent extractives also showed characteristic UV fluorescence at 254 and $365 \mathrm{~nm}$. M. oleifera fluoresces ash in methanol, chloroform and $1 \mathrm{~N} \mathrm{NaOH}$.

Phytochemical analysis showed the presence of saponins, tannins, alkaloids, glycosides, phenols, flavonoids, gums, and mucilages.

For the presence of heavy metals, $M$. oleifera showed the absence of Arsenic (As), Lead ( $\mathrm{Pb}$ ), Mercury ( $\mathrm{Hg}$ ), Chromium (Cr) and cadmium at a concentration of $0.02 \pm 0.003 \mathrm{ppm}$.

Bacterial and fungi count of the powdered sepals of M. oleifera were $10^{7}$ and $10^{4} \mathrm{CFU} / \mathrm{g}$ respectively. The WHO standards (World Health Organization, 2007) states that, the maximum bacteria and fungi count should be $10^{7}$ and $10^{4} \mathrm{CFU} / \mathrm{g}$ respectively. Therefore, the results were just within the limit.

\section{DISCUSSION/CONCLUSION}

Results from the physicochemical, phytochemical, heavy metal and microbiological analysis of Moringa oleifera leaves are all prerequisites to the quality assurance of this plant material. These parameters provide a simple means of detecting adulteration and substitution of this plant material. In so doing, they assure the safety and efficacy of this medicinal plant. Microscopic analysis, for example is important in the establishment of the identity and purity of particularly plant samples and serves as an initial screening test for impurities. ${ }^{22}$ Authentic $M$. oleifera leaves should therefore display rosette calcium oxalate crystals, polygonal epidermal cells and unicellular trichomes. The tripinnate description of the leaves is similar to those already published in the literature. $^{5}$

The $50 \%$ ethanol had an average soluble extractive of M. oleifera of $42 \% \mathrm{~W} / \mathrm{W}$, and this is higher than that of the water and petroleum ether soluble extractives. The extractive values indicate concentrations of extractable components present in the plant materials. ${ }^{23}$ Extractive values can also be useful as a physicochemical marker for the detection of already exhausted plant materials and possibly adulterated ones.

The total ash value, averaged $10 \% \mathrm{~W} / \mathrm{W}$, followed by the water and acid soluble values respectively. The values obtained in this study were considerably higher than those already published in the literature. ${ }^{24,25}$ These differences are likely due to the differences in methods of extraction. The total ash indicates the amount of physiological ash, which is attributed to mineral components such as magnesium calcium, and potassium and non-physiological ash attributed to the presence of soil components. This value will aid in the identification of low-grade products and the establishment of the purity of the material at hand. ${ }^{24,26}$

The water soluble ash is attributed to water soluble components of the plant material and indicates plant materials that could have been previously extracted. The acid insoluble ash also gives an account of the inorganic components in the plant materials such as silica ${ }^{27}$ or metals that may be present. These values will give an indication of the concentrations of various impurities that could affect the safety and efficacy of the plant material.

The presence of saponins, tannins, alkaloids, glycosides, phenols, and flavonoids as detected are already known to be present in this plant material in addition to terpenoids and glycosides. ${ }^{27-29}$

M. oleifera in different reagents displayed characteristic fluorescences under UV light. At $254 \mathrm{~nm} \mathrm{M}$. oleifera fluoresces pink in $\mathrm{NaOH}$, sulphuric acid, methanol and glacial acetic acid, while it flouresces ash in $\mathrm{NaOH}$ and methanol at $365 \mathrm{~nm}$. Results in ferric chloride, $\mathrm{NaOH}$ and sulphuric acid are slightly comparable to other published results. ${ }^{25}$ The differences can be attributed to the differences in the methods used. These characteristic colours may serve as useful parameters for the identification and subsequent quality control of the powdered leaves 
of $M$. oleifera. Flourescence is as a result of the presence of extended conjugated double bonds, ${ }^{30,31}$ hence a change in this fluorescent behaviour could indicate the presence of adulteration or substandard material which has resulted in a change in chemical composition of the plant material.

Few studies have surveyed the microflora present in samples of $M$. oleifera on the Ghanaian market. Even in doing so, values need to be compared to standard samples. For the authentic plant sample, the aerobic bacteria count was an average of $10^{7} \mathrm{CFU} / \mathrm{g}$ of dried plant material while the fungi count was $10^{4} \mathrm{CFU} / \mathrm{g}$. In comparison to WHO standards, the maximum aerobic bacteria and fungi count should be $10^{7}$ and $10^{4} \mathrm{CFU} / \mathrm{g}$, respectively. Therefore, the results were within acceptable limits. ${ }^{3}$ In conclusion, this study evaluated the morphological, physicochemical, phytochemical, heavy metal and microbiological parameters of $M$. oleifera leaves by available and straightforward methods. This is crucial for its standardization and to ensure the safe and it will ensure the safe and efficacious use of this medicinal plant.

\section{ACKNOWLEDGEMENTS}

The authors sincerely acknowledge Miss Hannah Amponsah and Mr. Francis Setsofia of the Department of Pharmacognosy and Herbal Medicine, and also Mr. Clement Sasu and Mrs. Akosua Okraku of the Department of Pharmaceutics and Microbiology for the technical assistances during the various experiments.

\section{CONFLICTS OF INTEREST}

None.

\section{REFERENCES}

1. Ekor M. The growing use of herbal medicines: issues relating to adverse reactions and challenges in monitoring safety. Front Pharmacol, 2014;4(177).

2. Patel C, Satanand T, Patel K, Patel T, Patel H,Patel P. Standardization of herbal medicine: A concise review. JPBR, 2014;2(1):97-101.

3. World Health Organization (WHO). Quality control methods for herbal materials. 2011, Geneva.

4. Goswami S, Singhai R. Evaluation of physicochemical parameters of Moringa oleifera leaves. FFI, 2015;21(2):169-72.

5. Paikra BK, Dhongade HKJ,Gidwani B. Phytochemistry and Pharmacology of Moringa oleifera Lam. J Pharmacopuncture, 2017;20(3):194-200.

6. Bhattacharya A, Tiwari P, Sahu PK,Kumar S. A Review of the Phytochemical and Pharmacological Characteristics of Moringa oleifera. J Pharm Bioallied Sci, 2018;10(4):181-91.

7. Oppong Bekoe E, Agyare C, Boakye YD, Baiden BM, Asase A, Sarkodie J, et al. Ethnomedicinal survey and mutagenic studies of plants used in Accra metropolis, Ghana. J. Ethnopharmacol, 2020;248(112309):1-12.

8. Maurya SK, Singh AK. Clinical efficacy of Moringa oleifera Lam. stems bark in urinary tract infections. Int. Sch. Res. Notices, 2014;2014:424-43.

9. Abd Rani NZ, Husain K,Kumolosasi E. Moringa Genus: A Review of Phytochemistry and Pharmacology. Front Pharmacol, 2018;9:108.
10. Vergara-Jimenez M., Almatrafi M. M.,Fernandez M. L. Bioactive Components in Moringa oleifera Leaves Protect against Chronic Disease. Antioxidants (Basel), 2017;6(4).

11. Kou X., Li B., Olayanju J. B., Drake J. M.,Chen N. Nutraceutical or Pharmacological Potential of Moringa oleifera Lam. Nutrients, 2018;10(3).

12. Rao K, Geetha K,Banji D. Quality control study and standardization of Hibiscus rosasinensis I. flowers and leaves as per WHO guidelines. J. Pharmacogn Phytochem, 2014;3(4):29-37.

13. Da-Costa-Rocha I. Hibiscus sabdariffa L.-A phytochemical and pharmacological review. Food Chem, 2014;126:424-43.

14. Quaye W, Gyasi O, Larweh P, Johnson PNT,Obeng - Aseidu P. The extent of marketability and consumer preferences for traditional leafy vegetables-a case study at selected markets in Ghana. Int. J. Consum., 2009;33(3):244-49.

15. Mahadevan N,Kamboj P. Hibiscus sabdariffa Linn. - An overview. Nat. Prod Rad, 2009;8(1):77-83.

16. Garg V, Dhar VJ, Sharma A,Dutt R. Facts about standardization of herbal medicine: A review. Chin. J Integr Med, 2012;10(10):1077-83.

17. Khandelwal K. Practical Pharmacognosy: Techniques and Experiments. 2002, Nirali Prakashan, New Delhi,.

18. Harborne JB. Phytochemical Methods. 1992, Chapman and Hall Publications: London.

19. Ranjith $D$ : . Fluorescence analysis and extractive values of herbal formulations used for wound healing activity in animals. J Med Plants Stud, 2018;6(2):18992.

20. Oppong Bekoe E, Dodoo KB, Kitcher C, Gordon A, Frimpong-Manso S,Schwinger G. Pharmacognostic Characteristics and Mutagenic Studies of Alstonia boonei De Wild. RJP, 2020;7(1):7-15.

21. Frimpong-Manso S, Magnus-Aryitey GT, Hevi D, Dombi G, Nyarko AK Boamah D, et al. Bioinorganic elemental content of the Ghanaian aphrodisiac medicinal plant, Paullina pinnata Linn.(Sapindaceae). Afri. J. Pharm. Pharmaco, 2016;10(11):206-11.

22. Kunle OF, Egharevba HO,Ahmadu PO. Standardization of herbal medicines - A review. Int. J. Biodivers. Conserv., 2012;4(3):101-12.

23. Folashade $\mathrm{O}$, Omoregie $\mathrm{H}, \mathrm{Ochogu}$ P. Standardization of herbal medicines-A review. Int. J. Biodivers. Conserv, 2012;4(3):101-12.

24. Bello Abdullahi A, Adamu U, Sallau Muhammad S, Okunola Oluwole J. Physical and phytochemicals study of some local herbal remedies. OSR-J Pharm Bio Sci., 2015; 10(4):5-10.

25. Pal SK, Mukherjee PK, SahaK, Pal M,Saha B.P. Some Pharmacognostic Characteristics of Moringa oleifera Lam. Leaves. Ancient Science of life 1996;XV 288-92.

26. Oppong Bekoe E, Kitcher C, Amponsah Agyei G,Frimpong-Manso S. Pharmacognostic Characteristics of Hibiscus sabdariffa L. as a Means of Monitoring Quality. Research Journal of Pharmacognosy (RJP), 2020;7(3):5563.

27. Ugwoke CEC, Eze KA, Tchimene KM,Anze SPG. Pharmacognostic Evaluation and Antimicrobial Studies on Moringa oleifera Lam. (Moringaceae). Int J Pharm Sci Res, 2017;8(1):88-94.

28. Sankhalkar S,Vernekar V. Quantitative and Qualitative analysis of Phenolic and Flavonoid content in Moringa oleifera Lam and Ocimum tenuiflorum L. Pharmacognosy Research, 2016;8(1):16-21.

29. KalappurayilTM, Joseph BP. A Review of Pharmacognostical Studies on Moringa oleifera Lam. flowers. Pharmacogn J., 2017;9(1):1-7.

30. Gayathri V,Kiruba D. Fluorescence Analysis of Two Medicinal Plants - Psidium guajava L And Citrus aurantium. Int. J. Pharm. Sci. Res., 2015;6(3):1279-82.

31. Chanda S. Importance of pharmacognostic study of medicinal plants: an overview. J Pharmacogn Phytochem, 2014;2(5):69-73. 


\section{GRAPHICAL ABSTRACT}

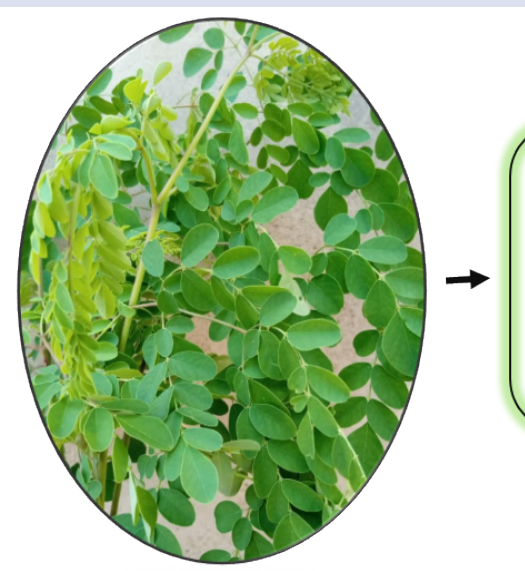

\section{Analysis}

Botanical, Physicochemical,

Phytochemical, Heavy metal,

Flourescence, Microbiological

\section{M. oleifera Lam}

Cite this article: Bekoe EO, Jibira Y, Agyei GA. Physicochemical, Phytochemical, Heavy Metal and Microbiological Analysis of Moringa oleifera Lam. Leaves. Pharmacogn J. 2020;12(6)Suppl:1541-6. 